\title{
Como criar uma paisagem em ruínas? Deslocamentos, desconstruções e a insistência de pensar a Educação Ambiental no Antropoceno
}

\author{
How to create a landscape in ruins? Displacements, deconstructions and the insistence on thinking
}

Environmental Education in the Anthropocene

\begin{abstract}
¿Cómo crear un paisaje en ruinas? Desplazamientos, desconstrucciones y la insistencia de pensar la Educación Ambiental en el Antropoceno
\end{abstract}

Shaula Maíra Vicentini de Sampaio - Universidade Federal Fluminense | Departamento de Biologia Geral | Niterói | RJ | Brasil. E-mail: shaula.maira@gmail.com

\begin{abstract}
Resumo: Este ensaio é sobre o processo de criar ruínas - por meio do radical estranhamento com relação a discursos que nos são caros, familiares e confortáveis - e passar a [gostar de] habitá-las. As ruínas criadas são o resultado de deslocamentos e desconstruções que efetuados por estudos afinados com perspectivas teóricas pós-estruturalistas. A proposta consiste em favorecer a invenção de outras paisagens em Educação Ambiental, nas quais não nos sintamos tão seguros, mas que talvez por isso mesmo sejam instigantes e desafiadoras por permitirem uma sensação de desorientação e desfamiliarização. A Educação Ambiental é constituída e marcada por verdades e certezas, tanto provindas do campo da educação quanto do que poderíamos chamar de "metanarrativas ambientais" - as verdades ambientais que nos interpelam. A fim de imprimir rasuras e instalar fissuras nessas metanarrativas, foram focalizadas provocações, ideias explosivas, vindas de dois "lugares" diferentes: a desconstrução dos conceitos de meio ambiente e natureza feita por Bruno Latour e colaboradores; e as mordazes críticas aos discursos ambientalistas feitas em um vídeo pelo filósofo Slavoj Žižek. A partir dessa insólita combinação, acredita-se ter provocado alguns desmoronamentos, algumas rachaduras, produzindo, quiçá, espaços vazios que venham a ser ocupados de formas inventivas pelos educadores ambientais.
\end{abstract}

Palavras-chave: Educação ambiental. Pós-estruturalismo. Antropoceno.

Abstract: This text is about the process of creating ruins - through the radical estrangement regarding speeches we hold dear, as for they are familiar and comfortable - and start [and enjoy] inhabiting them. The ruins created are the result of displacements and deconstructions which have been honed by studies in tune with post-structuralist theoretical perspectives. The proposal is to facilitate the invention of other landscapes in environmental education, in which one does not feel so safe, but perhaps, for that reason, such landscapes can be exciting and challenging as they lead to a feeling of disorientation and defamiliarization. Environmental education is organized and marked by truths and certainties, both from the education field (educational metanarratives), and from what we might call "environmental metanarrative", that is, environmental truths that circle around and reach us. In order to print erasures and cleave these metanarratives, some provocations and explosive ideas were focused on, coming from two different "places": the deconstruction of the concepts of environment and nature carried out by Bruno Latour and collaborators, and the scathing criticism of environmental discourses by the philosopher Slavoj Žižek. From this unusual combination one might expect to have triggered landslides, some clefts, resulting, perhaps, in empty spaces that will be occupied through inventive ways by environmental educators.

Keywords: Environmental education. Post-structuralism. Anthropocene.

Resumen: Este ensayo trata del proceso de crear ruinas - por medio del radical extrañamiento respecto a los discursos que nos son caros, familiares y cómodos - y pasar a [disfrutar de] habitarlas. Las ruinas producidas resultan de desplazamientos y desconstrucciones efectuados por estudios afinados con perspectivas teóricas posestructuralistas. La propuesta consiste en favorecer la invención de otros paisajes en Educación Ambiental, en los cuales no nos sintamos tan seguros, pero que tal vez por esa misma razón sean instigadores y desafiadores al permitir una sensación de desorientación y desfamiliarización. La Educación Ambiental es constituida y marcada por verdades y certezas, tanto provenientes del campo de la educación como de lo que podríamos denominar "metanarrativas ambientales" - las verdades ambientales que nos interpelan. Con el fin de imprimirles cortes e instalar fisuras en esas metanarrativas, se han focalizado provocaciones, ideas explosivas, oriundas de dos "lugares" diferentes: la desconstrucción de los conceptos de medio ambiente y naturaleza planteada por Bruno Latour y colaboradores; y las mordaces críticas a los discursos ambientalistas hechas en un vídeo por el filósofo Slavoj Žižek. A partir de esa insólita combinación, se cree haber provocado algunos desmoronamientos, algunas grietas, produciendo, a lo mejor, huecos que se puedan ocupar de formas inventivas por los educadores ambientales.

Palabras clave: Educación ambiental. Posestructuralismo. Antropoceno.

\footnotetext{
- Recebido em 29 janeiro de 2019 • Aprovado em 1 de março 2019 • e-ISSN: 2177-5796 DOI: https://doi.org/10.22483/2177-5796.2019v21n1p19-38
}

Copyright @ 2019. Conteúdo de acesso aberto, distribuído sob os termos da Licença Internaonal da CreativeCommons - CC BY-NC-SA Atribuição Não Comercial (https://br.creativecommons.org/licencas/) - Permite distribuição e reprodução, desde que atribuam os devido créditos à publicação, ao autor(es) e que licenciem as novas criações sob termos idênticos. 
SAMPAIO, Shaula Maíra Vicentini de. Como criar uma paisagem em ruínas? Deslocamentos, desconstruções e a insistência de pensar a Educação Ambiental no Antropoceno.

\section{Uma língua (im)possível}

Escrevo esse texto embalada pelas perguntas e provocações lançadas por Jorge Larrosa (2006) no texto "Una lengua para la conversación”. O autor expõe seu incômodo com relação à crença de que se falaria uma única língua no que ele chama de espaço educativo, entendido como a rede que se tece entre pesquisadores, especialistas, estudantes e professores preocupados com a questão da educação. Como ele explica: "todos os dias somos convidados a falar e a escutar, a ler e a escrever, a participar ativamente dessa gigantesca maquinaria de fabricação e circulação de informes, de projetos, de textos” (LARROSA, 2006, p. 25) ${ }^{1}$. Mas logo questiona: em que língua? Pode essa língua ser a nossa língua?

Como nos mostraram todos aqueles intelectuais que usualmente associamos ao movimento que foi designado como "virada linguística" com os quais dialogamos com maior ou menor intensidade, a nossa compreensão da realidade é mediada e atravessada pelas formas como, por meio da linguagem, descrevemos, moldamos e, assim, constituímos essa “realidade”. Ou, como diz Larrosa (2006, p. 28), "não há políticas da verdade que não sejam, ao mesmo tempo, políticas da língua". Se a língua funciona como um lugar de acolhimento e pertencimento, funciona também como um lugar de rechaço e exclusão daqueles que não a dominam, não a aceitam e não se submetem a seus imperativos (LARROSA, 2006). Arriscome a prolongar-me demais na argumentação do autor por considerar que ela favorece reflexões indispensáveis para as questões que serão abordadas neste texto. Larrosa pontua que no campo educativo prevalecem dois tipos de linguagem (que estão em constante tensão): a linguagem da técnica e a linguagem da crítica. A primeira é acionada por aqueles que nos dizem o que é; e a segunda pelos que invocam o que deveria haver ou deveria ser. Dito de outro modo, "a linguagem dos que falam em nome da realidade e dos que falam em nome do futuro" (LARROSA, 2006, p. 30).

Durante a leitura deste texto de Larrosa (2006), ocorreram-me alguns pensamentos que vêm me acompanhando há certo tempo, ainda que de forma não exatamente sistematizada. Tais pensamentos conectam-se com os modos como tenho buscado desenvolver pesquisas em Educação Ambiental, desde minhas primeiras - e indeléveis - aproximações dos referenciais teóricos pós-estruturalistas. Sendo assim, acredito que as lentes "pós", sejam elas

\footnotetext{
${ }^{1}$ As traduções são de minha responsabilidade.
} 
SAMPAIO, Shaula Maíra Vicentini de. Como criar uma paisagem em ruínas? Deslocamentos, desconstruções e a insistência de pensar a Educação Ambiental no Antropoceno.

denominadas de pós-modernas, pós-estruturalistas, pós-críticas ou pós-fundacionais ${ }^{2}$, podem deflagrar possibilidades interessantes, encontros, agenciamentos outros para as formas de pensar e fazer Educação Ambiental. Mas, necessariamente, em um primeiro momento, esses movimentos teórico-práticos provocam pequenas ou grandes implosões, rachaduras que põem em risco a estrutura que edifica e sustenta as verdades deste campo, imprimindo rasuras nas palavras que compõem o vocabulário dos educadores ambientais. Essas operações de desestabilização ou desconstrução de verdades e discursos que se encontram assentados e em nós entranhados, assemelhando-se ao que Larrosa (2006) chama de uma língua comum, produzem uma paisagem arruinada, uma Educação Ambiental em ruínas - ao menos para aqueles que, como eu, enveredaram por estas searas teóricas. É sobre esse processo de criar ruínas, por meio do radical estranhamento com relação a discursos que nos são caros, familiares e confortáveis e passar a [gostar de] habitá-las, que desejo falar neste texto.

Caberia, inicialmente, propor algumas questões na cadência dos escritos do filósofoeducador catalão: haveria uma língua comum aos educadores ambientais ou ao menos a pretensão de se consolidar algum dia tal língua? Não hesito em responder afirmativamente a essa pergunta, nem me eximo da participação neste empreendimento. Como uma pessoa que vem, desde os tempos de graduação, se identificando com o ideário ambientalista, envolvendo-se em diferentes espaços de interlocução (acadêmicos ou não) e investindo na constituição de uma identidade de educadora ambiental, encontro-me enredada nas discursividades que buscam instituir a Educação Ambiental como um campo legítimo no espaço educativo contemporâneo.

É preciso considerar, porém, como vêm mostrando alguns autores como (CARVALHO, 2001; 2004), que a Educação Ambiental vem sendo engendrada em movimentos de aproximações e afastamentos com relação aos discursos mais propriamente vinculados ao campo da educação. Quanto a isso, interessa-me somente ressaltar que uma suposta língua da Educação Ambiental guarda muitas afinidades com a língua do espaço educativo. Uma das semelhanças diz respeito justamente à combinação da língua dos técnicos com a língua dos críticos. Isto é, observamos um movimento que visa consolidar um espaço de legitimação de determinadas verdades, baseadas sobretudo no saber científico, as quais auxiliam na planificação de uma agenda de ações para alcançar resultados preestabelecidos,

\footnotetext{
${ }^{2}$ Por mais que a menção destas distintas inflexões teórico-metodológicas requeira maiores definições ou o estabelecimento de contornos e distinções mais precisos, assim como se façam necessárias problematizações mais detalhadas, não caberia realizar estas operações no âmbito deste artigo.
} 
SAMPAIO, Shaula Maíra Vicentini de. Como criar uma paisagem em ruínas? Deslocamentos, desconstruções e a insistência de pensar a Educação Ambiental no Antropoceno.

sejam eles a diminuição de impactos ambientais, o manejo "correto" dos recursos naturais, a redução da produção de lixo ou do desperdício de água etc. E, por outro lado (mas não raro de forma imbricada), uma entonação crítica da Educação Ambiental acentua a necessidade de entender a mesma como uma prática política direcionada à realização de certos ideais ligados à construção da cidadania, à construção de formas mais éticas de nos relacionarmos com os outros seres vivos, à necessidade de que nos preocupemos com o mundo que será herdado pelas gerações futuras.

E, como lembra Larrosa (2006, p. 30-31), dirigindo à educação uma reflexão que pode trazer alguns deslocamentos instigantes para pensarmos também a Educação Ambiental:

\begin{abstract}
A educação, segundo dizem, deve partir da realidade, o campo pedagógico é um gigantesco dispositivo de produção de realidade, de uma certa realidade. Como a educação, segundo dizem, deve transformar o que há através da sua própria transformação, o campo pedagógico fabrica incansavelmente projetos para a prática, para uma certa prática. Nossa língua, nos dizem, tem que ser ao mesmo tempo realista, prática e progressista. [...] Mas essa linguagem nos parece vazia e está se tornando impronunciável (grifos do autor).
\end{abstract}

Inquieta-me reconhecer essa sensação de vazio que geram determinadas palavras e frases que se tornaram quase esgarçadas de tão pronunciadas (inclusive por mim) e sem saber ao certo quais palavras restam para imaginar uma Educação Ambiental que possa ser habitada por aqueles que ainda não conhecem nem dominam suas regras sintáticas, sua semântica. Que língua poderia ser ativada pela Educação Ambiental de modo a propiciar sensações e produções diferentes daquelas com as quais já estamos confortavelmente acostumados? Seria interessante almejar uma língua por meio da qual todos pudéssemos nos entender? Haveria como promover algumas invenções (ou infrações) a partir de elementos próprios a uma gramática da Educação Ambiental? Poderíamos brincar de criar novos significados para palavras que já existem? Conseguiremos colocar sob rasura alguns significados da Educação Ambiental que nos constituem? São algumas indagações que vêm à mente ao articular as questões abordadas por Larrosa com os meus pensamentos sobre Educação Ambiental.

São perguntas que gostaria de deixar ressoando sem respostas imediatas, mesmo porque talvez nem sequer possuam respostas.

\title{
Desnaturalizar, desconstruir, deslocar, desmanchar...
}

O movimento expresso nos verbos que compõem o título desta seção tem um papel fundamental na condução de pesquisas orientadas pelos referenciais teóricos pós- 
SAMPAIO, Shaula Maíra Vicentini de. Como criar uma paisagem em ruínas? Deslocamentos, desconstruções e a insistência de pensar a Educação Ambiental no Antropoceno.

estruturalistas. Poder-se-ia dizer até mesmo que se trata de um pré-requisito de tais investigações. Não no sentido de se criar um método para fixar procedimentos ou instituir etapas rigidamente delimitadas, mas sim no sentido de que é muito difícil que um estudo pósestruturalista não promova alguma problematização acerca dos modos como usualmente se vê ou pensa o "objeto" ou "tema" de pesquisa, ou dos modos como historicamente fomos sendo ensinados a ver ou pensar de uma determinada maneira. Vamos, assim, desenvolvendo o hábito de desconfiar de tudo aquilo que se nos apresenta como evidente, consensual e, até mesmo, imprescindível. E desse jeito vamos aprendendo a colocar em jogo as nossas próprias verdades e certezas. Como mencionei anteriormente, no campo da educação e na Educação Ambiental, abundam certezas e verdades sobre o que o mundo necessita, sobre o que os outros necessitam, sobre o que deve ser a escola, sobre como podemos salvar o planeta, sobre a necessidade de sermos críticos. Como afirmou Alfredo Veiga-Neto (2002, p. 23), devemos "desconfiar das bases sobre as quais se assentam as promessas e as esperanças nas quais nos ensinaram a acreditar. Tudo indica que deveremos sair dessas bases para, de fora, examiná-las e criticá-las".

Mais de duas décadas após a publicação do texto "O adeus às metanarrativas educacionais", seguem sendo extremamente pertinentes e atuais as questões apresentadas por Tomaz Tadeu da Silva (1994) nesta ocasião. A pergunta que norteia as reflexões do autor que elementos do edifício teórico-educacional são abalados pelas reconceptualizações do pósestruturalismo e do pós-modernismo? - continua ecoando nos espaços acadêmicos de interlocução e, recentemente, tem inquirido com mais intensidade os educadores ambientais. Ao explorar as reverberações dessa indagação, o autor avalia que esses abalos são de várias ordens e afetam o cerne dos discursos pedagógicos, o que ele chama de metanarrativas educacionais. Estas dizem respeito, sobretudo, às noções de sujeito, consciência, razão, entre tantas outras e especialmente aos arranjos discursivos comumente associados às ditas pedagogias críticas. Como ressaltou o autor (SILVA, 1994, p. 250), a perspectiva pósestruturalista "subverte todas as nossas mais queridas noções sobre educação, incluindo aquelas que tínhamos como mais críticas e transgressivas. Nisso reside a sua força".

Em sua análise aguçada, o autor nos auxilia a compreender como as melhores intencionadas ações educativas estão imersas em relações de saber-poder. Como as mais altruístas atitudes educativas destinadas a contribuir com a construção de indivíduos reflexivos, conscientes de suas relações com o meio e aptos a atuar coletivamente em prol de 
SAMPAIO, Shaula Maíra Vicentini de. Como criar uma paisagem em ruínas? Deslocamentos, desconstruções e a insistência de pensar a Educação Ambiental no Antropoceno.

uma causa comum, estão, sim, engajadas na promoção e instituição de um modo visto como mais verdadeiro de compreender e se relacionar com o mundo. E isso não as torna piores ou as invalida enquanto ações educativas importantes ou necessárias. O que se questiona é o entendimento de que tais ações estariam imunes às relações de poder ou, até mesmo, de que buscariam libertar (ou emancipar) as pessoas de estruturas de poder, tornando-as críticas e autônomas. Como enfatiza Silva (1994, p. 251), “o saber do intelectual [ou do educador] não paira acima e fora das lutas e relações de poder: é parte integrante e essencial delas".

Assim como na educação, em Educação Ambiental nos deparamos com metanarrativas, algumas das quais são provenientes do campo da educação, tendo em vista a grande influência das teorias críticas educacionais nos escritos dos autores-fundadores da Educação Ambiental. Mas encontramos também, na educação ambiental, o que poderíamos chamar de "metanarrativas ambientais", ou seja, as verdades ambientais que circulam e nos interpelam com uma constância e força cada vez mais acentuadas nas últimas décadas. Enunciados e imagens sobre como deve ser um ambiente, como devem ser nossas atitudes com relação a este ambiente, como devem ser os sujeitos sustentáveis, circulam nas mais variadas instâncias, convidando-nos, incitando-nos, modulando-nos, esverdeando-nos.

Então, gostaria de destacar um pensamento que carece de um esforço argumentativo (e investigativo) mais sistemático, mas que proponho como um tópico que merece uma reflexão mais cuidadosa no futuro, a saber: com a desconfiança generalizada perante às metanarrativas da modernidade (incluindo aquelas mais estreitamente relacionadas ao campo da educação), vem emergindo na contemporaneidade um novo tipo de "grande narrativa" vinculada aos discursos sobre o meio ambiente e a sustentabilidade. Em outras palavras, argumento que, ao mesmo tempo em que se desestruturam outras certezas construídas na modernidade, os discursos sobre meio ambiente e sustentabilidade têm se tornado uma espécie de verdade inquestionável, imiscuindo-se e articulando diferentes âmbitos da vida contemporânea (desde a esfera do privado até a coletividade).

Essas narrativas têm conseguido disseminar-se amplamente no tecido social, buscando difundir preocupações importantes relativamente à sobrevivência da nossa espécie e dos demais seres vivos, à manutenção de um ambiente sadio que possibilite que as sociedades tenham uma boa qualidade de vida, aos severos impactos ambientais ocasionados pelas atividades humanas, aos recursos de que irão dispor os habitantes deste planeta nas próximas gerações, entre outras questões fundamentais. Portanto, caberia indicar que o cerne das operações de deslocamento, desconstrução e desnaturalização com relação aos discursos da 
SAMPAIO, Shaula Maíra Vicentini de. Como criar uma paisagem em ruínas? Deslocamentos, desconstruções e a insistência de pensar a Educação Ambiental no Antropoceno.

Educação Ambiental não seria colocar em questão a existência de uma crise ambiental que tem efeitos concretos nas vidas de todos nós e que está ligada à crise de um modelo de desenvolvimento consagrado a partir de uma determinada configuração histórica, filosófica, cultural, científica e social, como já mostraram inúmeros estudiosos do campo ambiental ver, por exemplo Grün (1996) e Scotto; Carvalho; Guimarães (2007). Não obstante, considero ser imprescindível analisar detidamente a maneira como esses enunciados e imagens sobre meio ambiente, natureza e sustentabilidade vêm sendo disseminados nos nossos tempos, adentrando escolas e outros espaços educativos formais ou não, sendo veiculados ostensivamente pela mídia, compondo programas de governo destinados a tornar a Educação Ambiental um tema presente em todos os níveis de ensino. Ou seja, penso ser pertinente atentar para o modo como estamos sendo ensinados a usar um vocabulário da sustentabilidade, a adotarmos atitudes ecológicas nas nossas ações mais banais e, inclusive, a nos tornarmos educadores ambientais que buscam propagar esse vocabulário e essas atitudes.

Assim, julgo ser necessário verificar, a partir do que aprendemos com Michel Foucault (2003), como as verdades ambientais que nos constituem no tempo presente buscam conduzir nossas condutas, nos subjetivando e nos governando em direção a determinados fins. Lembrando que no interior das relações de poder, todos consentem ativamente em fazer parte destas relações (VEIGA-NETO, 2005), isto é, não somos obrigados a adotar o vocabulário e as atitudes voltados para a preocupação com o meio ambiente, mas o fazemos porque somos compelidos, educados, subjetivados a desempenhar um papel ativo na construção de uma sociedade sustentável. Como exorta Veiga-Neto, com base na obra de Foucault, compreender o poder em sua positividade significa entendê-lo como a ação de produzir alguma coisa. Nessa direção, nas malhas do poder os indivíduos "nunca são o alvo inerte e consentido do poder, são sempre centros de transmissão. Em outros termos, o poder não se aplica aos indivíduos; passa por eles" (VEIGA-NETO, 2005, p. 151).

Assim, penso que é importante pensarmos cuidadosamente sobre as verdades que nos constituem, pois ainda que desejemos nos engajar em sua defesa é interessante estarmos atentos às formas como as estamos defendendo. Como verdades incontestes e fechadas que queremos outros tomem como suas ou como políticas de verdade que se encontram em constante construção e que podem vir a ser, inclusive, contestadas e transgredidas? 
SAMPAIO, Shaula Maíra Vicentini de. Como criar uma paisagem em ruínas? Deslocamentos, desconstruções e a insistência de pensar a Educação Ambiental no Antropoceno.

\section{Provocações: meios ambientes e(m) ruínas}

Nesta seção gostaria de focalizar algumas provocações que me parecem bastante interessantes para que se possa imprimir alguns deslocamentos produtivos nos enunciados da educação ambiental. Provocações que permitem suspeitar de articulações que estejam muito

sedimentadas e, assim quem sabe, potencializar contaminações nestes enunciados, promover rotas de fuga. Por outro lado, são ideias lançadas aqui, como palpites, já que neste ensaio não tenho a preocupação de provar, estabelecer verdades. O movimento aqui é o contrário disso: busco questionar, provocar, abrir brechas nas verdades, coloniza-las com novos sentidos quem sabe? São ideias que me incitam a pensar e acredito que possam gerar efeitos positivos nas reflexões sobre as articulações entre educação e ambiente. Para isso, busco aproximações de autores que não necessariamente dialogam; são de campos teóricos distintos e, ao conversar com eles, não tenho a menor intenção de compor uma abordagem coerente e unificada. São elementos que podem ser pensados como composições fragmentárias de uma paisagem em ruínas.

Sobre essa imagem da ruína, que me parece uma metáfora instigante para imaginarmos a Educação Ambiental por meio das lentes pós-estruturalistas, trago as palavras de Antonio Carlos Amorim (2003) sobre o "percurso-ruína”, compreendido por ele como um plano de composição das produções curriculares pensadas como abrigos produzidos para conceitos, expressões, que estão abandonados, sem ninguém dentro. Assim, a ruína remete a uma paisagem em destroços, em que tudo está por fazer, em que as verdades erigidas há muito tempo estão suspensas ou estilhaçadas, onde mesmo as construções que conseguiram se manter em pé estão ameaçadas, podendo ruir a qualquer momento e, por isso, se encontram vazias, sem ninguém dentro. Isso não significa que não possamos visitar, percorrer, nos arriscar por entre os escombros. Seria interessante, porém, que fizéssemos novos usos desses elementos que permaneceram e que, se tentássemos habitar essas ruínas, o fizéssemos de formas inusitadas, sem a pretensão de construir novas fortalezas com a ilusão de segurança e eternidade, aceitando a instabilidade e a provisoriedade das nossas construções discursivas. Uma tarefa difícil, sem dúvida.

Sendo assim, a primeira das provocações que trago provém das instigantes discussões propostas por Bruno Latour, Cécile Schwartz e Florian Charvolin (1998) num texto do final do século passado, mas ainda bastante atual, intitulado "Crises dos meios ambientes: desafios 
SAMPAIO, Shaula Maíra Vicentini de. Como criar uma paisagem em ruínas? Deslocamentos, desconstruções e a insistência de pensar a Educação Ambiental no Antropoceno.

às ciências humanas". Neste texto os autores problematizam a construção contemporânea da categoria "meio ambiente", mostrando o quanto ela é recente e artificial. Neste texto que pretendo enfocar aqui, assim como em seus trabalhos mais recentes, Latour centra sua argumentação especialmente nos discursos relativos aos conceitos de natureza/meio ambiente, lançando alguns questionamentos no mínimo pertinentes.

Dessa forma, Latour, Schwartz e Charvolin (1998) apresentam uma série de questões bastante relevantes para pensarmos (e desconstruirmos) os processos articulatórios implicados na construção, não somente do uso que fazemos atualmente da palavra "meio ambiente", mas também da própria Educação Ambiental, como prática discursiva baseada em uma porção de “consensos" quase inquestionáveis. Os autores dedicam-se especificamente a pensar nos desafios que a "invenção" do meio ambiente impõe para as ciências humanas. Um dos principais aspectos salientados relativamente a essa invenção diz respeito à construção de um meio ambiente global e singular, o que é uma significativa inovação, já que antes meio ambiente era enunciado no plural, flexionado conforme os sentidos atribuídos a ele pelas diferentes culturas. Nas palavras dos autores: "tantas culturas, tantas sociedades, quantos meios ambientes - no plural" (LATOUR; SCHWARTZ; CHARVOLIN, 1998, p. 92). Eles consideram, entretanto, que o que está em jogo nessa unificação do meio ambiente não é um repentino desvelamento de uma Natureza que se encontrava esquecida ou renegada, mas se trata de uma nova organização das múltiplas traduções sociais dessa natureza.

Essa nova leitura da natureza engloba o que os autores definem como uma impressionante inversão antropológica, na medida em que a natureza, antes vista como ameaçadora e selvagem, converte-se em algo frágil e ameaçado, necessitando ser protegido “contra o maior perigo de todos, isto é, nós mesmos, os humanos" (LATOUR; SCHWARTZ; CHARVOLIN, 1998, p. 96). Por outro lado, supor a unidade do meio ambiente como se ela já estivesse dada ou que tivéssemos desde sempre um só ecossistema ameaçado e fosse imoral modificá-lo, é descartar o que existe de novo e interessante no horizonte das ciências humanas atualmente. Nessa direção, os autores argumentam que

\footnotetext{
a grande debilidade do debate público sobre o meio ambiente consiste em que as posições permanecem a-históricas. [Pois] supõe-se que os fatos tenham existido desde sempre, e não tenham sido moldados por ninguém. Supõe-se que os valores sejam transcendentes. $O$ caráter experimental da construção do meio ambiente não é reconhecido (LATOUR; SCHWARTZ; CHARVOLIN, 1998, p. 108, grifo meu).
}

A crítica feita pelos autores sinaliza para um caminho que conduz a analisar mais detidamente as condições socioculturais por meio das quais se engendram as articulações 
SAMPAIO, Shaula Maíra Vicentini de. Como criar uma paisagem em ruínas? Deslocamentos, desconstruções e a insistência de pensar a Educação Ambiental no Antropoceno.

que se produzem no campo ambiental de forma a tratá-las não como unidades, senão como conexões provisórias, nunca definitivas, mesmo que aparentemente indissolúveis. Ademais, considerar tais deslocamentos propostos relativamente à noção de "meio ambiente" pode resultar em uma grande amplitude de desdobramentos tanto em pesquisas quanto em práticas de Educação Ambiental, reverberando em uma série de outros discursos e imagens instituídos por esse espaço discursivo. Caberia indagar, por exemplo, sobre quais seriam as implicações para a Educação Ambiental de falar sobre meio ambiente (ou natureza) no plural, evitando reificar e naturalizar uma determinada forma de pensar sobre esses termos. Portanto, os escritos desses autores nos convidam a pensar de uma forma bastante original (e complexa) sobre meio ambiente e natureza, pois propõem rupturas profundas com relação aos modos usuais como as questões ambientais vêm sendo discutidas e entendidas atualmente.

Uma dessas rupturas pode estar vinculada ao argumento de que "toda fala sobre o que pode ou não um meio ambiente supõe um porta-voz" (LATOUR; SCHWARTZ; CHARVOLIN, 1998, p. 118) e na nossa sociedade certos porta-vozes - os cientistas - são tão pouco contestados que parece que eles transmitem exatamente o que dizem seus representados (as árvores da floresta, os ursos polares, as bactérias, os sapos, etc.). Contudo, "nenhum elemento da natureza, nenhuma reação química, nenhuma nuvem, nenhuma minhoca, nenhum plasmídeo, nenhuma baleia, fala diretamente" (LATOUR; SCHWARTZ; CHARVOLIN, 1998, p.119). O que ocorre é que os porta-vozes traduzem seus interesses uns nos outros, e o resultado dessas traduções é uma negociação sobre a forma que devem assumir os interesses. Em outro texto, Latour esclarece um pouco mais a proposição desta ideia de cientista como porta-voz de seres não humanos:

\begin{abstract}
os cientistas não são tão confusos a ponto de crerem que as partículas, os fósseis, as economias, os buracos negros, causem sozinhos, sem intermediários, sem investigação e sem instrumento, enfim, sem um aparelho de fonação, uma fabulosa complexidade e uma extrema fragilidade. Se alguém é tão louco afirmando que os fatos falam por si mesmos, ninguém tampouco dirá que os cientistas falam sozinhos a propósito de coisas mudas. [...] Diremos, portanto, que os cientistas inventaram aparelhos de fonação que permitem aos não humanos participarem nas discussões dos humanos [...] (LATOUR, 2004, p.128-129, grifos do autor).
\end{abstract}

A partir desse entendimento, no livro "Políticas da Natureza", Latour (2004) apresenta a ousada proposta de que o papel da ecologia política seria propiciar uma reunião do coletivo formado por humanos e não humanos. Tal coletivo não seria uma simples soma entre natureza e sociedade, pois não deveríamos nos preocupar mais "com os antigos títulos que determinavam a uns tomar assento nos vãos da natureza, e os outros sobre os bancos da 
SAMPAIO, Shaula Maíra Vicentini de. Como criar uma paisagem em ruínas? Deslocamentos, desconstruções e a insistência de pensar a Educação Ambiental no Antropoceno.

sociedade" (LATOUR, 2004, p. 117). O primeiro passo para compor tal coletivo seria passar a duvidar dos porta-vozes (cientistas e outros representantes dos seres não humanos).

Mas poderíamos indagar: como convocar as naturezas para participar do coletivo sem a mediação de tais porta-vozes? Essa é a intrincada questão sobre a qual Latour se debruça ao longo das páginas do seu livro e que não haveria como aqui esmiuçar. O que me parece bastante interessante é pensar como podemos nos posicionar diante destes radicais deslocamentos com relação a alguns conceitos preciosos para a Educação Ambiental. Se trouxe estes fragmentos das reflexões de Latour e seus colaboradores foi porque acredito que as mesmas podem ser muito produtivas para pensarmos nossas ações em Educação Ambiental. Como não singularizar natureza/ambiente? Como promover olhares e pensamentos para as naturezas no plural? Como podemos nos relacionar com os seres não humanos sem uma dependência tão grande dos mesmos porta-vozes de sempre? Seria interessante multiplicar os porta-vozes? Ou melhor seria eliminar essa ventriloquia? Os educadores ambientais seriam porta-vozes dos seres não-humanos ou amplificadores das vozes dos cientistas? E ainda: será que essa proposta de pensarmos em novas formas de inventar coletivos entre humanos e não humanos pode trazer contribuições para Educação Ambiental? Ou será que essa forma de pensar sobre natureza e meio ambiente produziria outra coisa radicalmente diferente da Educação Ambiental? As rasuras impressas por Latour, Scwartz e Charvolin (1998) no conceito meio ambiente tornariam uma Educação Ambiental impossível? São questionamentos que me ocorrem e ainda ressoam sem resposta, como um convite para pensar (depois de lermos e relermos os escritos de Latour).

A outra ideia explosiva (porque criadora de ruínas) que gostaria de lançar neste texto provém de um fervilhar de pensamentos desencadeados por um vídeo que assisti no YouTube. Este vídeo é protagonizado pelo "filósofo-marxista-lacaniano-celebridade" Slavoj Žižek $(2018)^{3}$, que discorre sobre sua visão do que seria uma "ecologia radical". Ainda que o autor possua certa aproximação do campo dos estudos culturais, ver, por exemplo, (ŽIŽEK, 2005), não estou propondo um mergulho em suas teorizações. $\mathrm{O}$ meu objetivo aqui é colocar em destaque precisamente as questões levantadas pelo filósofo no referido vídeo e não me

\footnotetext{
${ }^{3}$ Este vídeo intitula-se "A ecologia radical de Slavoj Žižek" e tem cerca de 10 minutos, até o momento desta pesquisa conta mais de 20 mil acessos. Não há maiores informações sobre a origem do vídeo. Parece tratar-se de um programa televisivo. Cabe referir que o filósofo possui uma forte inserção midiática devido ao seu estilo direto, provocativo e, ao mesmo tempo, acessível. Já participou duas vezes do programa de entrevistas brasileiro Roda Viva, é narrador do documentário "O guia pervertido do cinema" e já foi candidato à presidência do seu país.
} 
SAMPAIO, Shaula Maíra Vicentini de. Como criar uma paisagem em ruínas? Deslocamentos, desconstruções e a insistência de pensar a Educação Ambiental no Antropoceno.

interessa penetrar, pelo menos neste momento, na sua obra. Nele, o filósofo surge caminhando por um lugar que parece ser um aterro sanitário: uma paisagem caótica, repleta de entulho, sucata, lixo, fumaça, barulho de tratores. A sua primeira frase é: "Este é o lugar em que deveríamos nos sentir em casa. Parte da nossa percepção de realidade é que isso [aponta o lixo ao seu redor] desaparece do nosso mundo. [...]. Mas o problema é que o lixo não desaparece" (ŽIŽEK, 2018).

Ele prossegue dizendo que a ecologia compõe, hoje, uma parte importante da ideologia atual, como já foi um dia a religião. Isto é, para Žižek (2018), a ecologia tornou-se uma autoridade inquestionável por lidar com o tema da sobrevivência humana. Se um dia a religião foi responsável por assegurar o destino das almas, a ecologia torna-se responsável pela garantia da sobrevivência dos corpos (dos atuais e futuros habitantes humanos e não humanos do planeta). Como destaquei anteriormente, pode-se pensar nos discursos ecológicos como uma poderosa narrativa que está em ação neste início do século XXI (ainda que suas condições de emergência tenham se dado a partir das últimas décadas do século XX). Por conseguinte, não se refutam os discursos ecológicos porque não se refuta a necessidade de continuarmos vivendo neste planeta. Por essa razão, neste vídeo, o filósofo afirma que a ecologia está assumindo o papel de uma ideologia conservadora, que sempre nos aconselha a

\footnotetext{
não ir além, não ultrapassar um certo limite invisível: 'Não faça isso, seria demais'. Essa voz é hoje, cada vez mais, a voz da ecologia. 'Não bagunce com o DNA'. 'Não bagunce com a natureza'. 'Não faça'. Este conservadorismo básico, quase ideologicamente desconfiado de qualquer mudança, isso é a ecologia hoje em dia (trecho do vídeo), (ŽIŽEK, 2018).
}

Em uma outra entrevista, Sanín (2010) afirma que a versão predominante da ecologia é a ecologia do medo, que se manifesta pelo medo de uma catástrofe que possa erradicar a civilização humana. E por isso o seu caráter conservador, que visa impor limites para as ações humanas com o intuito de evitar, a qualquer custo, o fim (da espécie, da civilização, da vida...). Grün (1995) associa a emergência do "medo ecológico" ao advento da bomba atômica, que levou a humanidade a se deparar concretamente com o seu poder (auto) destrutivo. Garré e Henning (2013) aprofundam-se na discussão do que chamam de enunciado do terror e do medo no discurso ambientalista. Essas autoras ressaltam que os discursos catastróficos mobilizam uma série de sensações que se produzem em nós, como o sentimento de urgência que se adere às questões ambientais e a promoção de um sentimento generalizado de culpa pelos males cometidos contra a natureza. A partir da análise de reportagens publicadas na revista Veja, Garré e Henning (2013) enfatizam que as enunciações 
SAMPAIO, Shaula Maíra Vicentini de. Como criar uma paisagem em ruínas? Deslocamentos, desconstruções e a insistência de pensar a Educação Ambiental no Antropoceno.

apocalípticas no discurso ambiental culpabilizam as pessoas pelos problemas ambientais, repassando a cada indivíduo o compromisso de dirigir ao máximo seus esforços para tentar minimizar tal quadro aterrorizante.

Certamente, esses enunciados não se restringem à revista analisada pelas autoras, tendo em vista que é bastante comum encontrarmos chamamentos, nos mais diversos produtos midiáticos, dizendo que a Terra pede socorro, que o fim do mundo se aproxima e os culpados somos nós ou mesmo que o planeta prepara uma vingança contra seus algozes. O afã de encontrar culpados pela crise ecológica é explicado por Žižek (2018) no vídeo da seguinte maneira:

Quando uma coisa horrível acontece, nossa tendência espontânea é buscar um sentido. 'Precisa fazer sentido'. [...] Então, os conservadores vêm e dizem que é uma punição pelos pecados que cometemos e assim por diante. E quando entendemos uma catástrofe como uma punição fica mais fácil de engolir porque sabemos que não se trata de uma força cega. Tem um sentido. É melhor quando estamos no meio de uma catástrofe. É melhor sentir que Deus esteja nos punindo do que sentir que é apenas um acaso.

E como fazer para tentar expiar essa culpa antes que a punição - na forma de aquecimento global, desertificação, esgotamento de recursos, entre outros desastres de grande magnitude - nos seja infligida? Nas palavras de Godoy (2008, p. 102), "a ecologia torna-se o arauto das medidas profiláticas que nos permitirão viver”. Por conseguinte, algumas alternativas que vêm sendo propostas convocam-nos a mudarmos nossos hábitos, nossas ações mais corriqueiras, incorporando a preocupação com o meio ambiente em cada ato da nossa rotina. Todos devemos nos tornar sujeitos sustentáveis, cidadãos conscientes do nosso papel na engrenagem civilizatória que nos trouxe a esse impasse. Indivíduos que experimentamos a ambiguidade de viver num mundo em que somos mais e mais instigados a consumir objetos fantásticos que se sucedem (e caducam) numa velocidade nunca antes vista e, ao mesmo tempo, carregamos nas costas a culpa por termos criado o pior dos mundos, para me valer da bela expressão de Godoy (2008). Entretanto, se na distribuição da culpa cada um de nós deve arcar com a sua parcela, tais discursos nos ensinam também que pouca ingerência temos sobre os mecanismos dessa engrenagem, que envolve políticas de estado, empresas transnacionais, conglomerados comunicacionais.

O que cada um pode fazer, então, se o slogan "faça a sua parte" é provavelmente apenas um placebo para lidar com o mal-estar gerado pela "culpa ecológica"? Refletir sobre essas questões não raro provoca um sentimento de impotência. Talvez por essa razão, Žižek 
SAMPAIO, Shaula Maíra Vicentini de. Como criar uma paisagem em ruínas? Deslocamentos, desconstruções e a insistência de pensar a Educação Ambiental no Antropoceno.

(2018) afirme que tendemos a reagir de uma forma peculiar com relação aos problemas ambientais: negando-os. No vídeo que estamos abordando, ele explica da seguinte maneira:

\begin{abstract}
A lógica disso funciona assim: 'eu sei muito bem, mas ajo como se não soubesse'. Por exemplo, no caso da ecologia, sei muito sobre o que pode ser o aquecimento global, que tudo pode explodir, ser destruído. Mas após ler um livro sobre o assunto, o que faço? Eu paro e vejo - não as coisas atrás de mim [aponta a montanha de lixo] [...]. Eu vejo árvores, passarinhos cantando, etc. E mesmo que saiba conscientemente de todos os perigos, simplesmente não creio que tudo possa ter um fim. Isso é o chocante de visitar lugares de catástrofe como Chernobyl (trecho do vídeo).
\end{abstract}

A negação apontada pelo filósofo estaria associada ao fato de preferirmos (enquanto ambientalistas, cientistas, educadores, jornalistas, políticos...) pensar no meio ambiente enquanto paisagens preservadas, intocadas ou bucólicas ao invés de assumirmos que o meio ambiente que produzimos é muito mais parecido com o cenário desolador em que ele se encontra. Como se vivêssemos na cidade de Leônia, inventada por Ítalo Calvino, optamos por não querer ver as montanhas de lixo que nos circundam e crescem vertiginosamente:

Ninguém se pergunta para onde os lixeiros levam os seus carregamentos: para fora da cidade, sem dúvida; mas todos os anos a cidade se expande e os depósitos de lixo devem recuar para mais longe; a imponência dos tributos aumenta e os impostos elevam-se, estratificam-se, estendem-se por um perímetro mais amplo. Acrescentese que, quanto mais Leônia se supera na arte de fabricar novos materiais, mais substancioso torna-se o lixo, resistindo ao tempo, às intempéries, à fermentação e à combustão. E uma fortaleza de rebotalhos indestrutíveis que circunda Leônia domina-a de todos os lados como uma cadeia de montanhas (CALVINO, 1990, p. 106).

E o que poderíamos fazer para não negar essa paisagem aterradora? $\mathrm{O}$ que poderiam fazer os habitantes de Leônia se chegassem a pisar nas camadas mais externas dessa cidade que cresce como um tumor em direção ao resto do mundo? Como não desviar o olhar (e o nariz) e encarar este fétido meio ambiente que produzimos ao invés de optarmos por olhar para as árvores e passarinhos que Žižek (2018) menciona em sua fala no vídeo? De que maneira não ficar perplexo de encantamento diante das avassaladoras fotografias da exposição Gênesis de Sebastião Salgado e não sofrer com o fato de que provavelmente transformaremos as paradisíacas paisagens retratadas pelo artista em novos lixões, em novos desertos? São alguns questionamentos que me atormentam quando reflito sobre as proposições de Žižek e suas implicações para a Educação Ambiental no Antropoceno. As ruínas desorientam mesmo aqueles que, como eu, contribuem ativamente com a sua produção. 
SAMPAIO, Shaula Maíra Vicentini de. Como criar uma paisagem em ruínas? Deslocamentos, desconstruções e a insistência de pensar a Educação Ambiental no Antropoceno.

Nesse ponto, considero ser necessário retomar aspectos que têm sido muito discutidos e destacados por pesquisadores que se propõem a articular Educação Ambiental e estudos culturais, quais sejam: a) não há um discurso unitário para se falar de natureza, b) a natureza é construída de diferentes formas nas mais diversas instâncias culturais e c) o olhar naturalista é produzido a partir de circunstâncias históricas, sociais e culturais específicas, não sendo nem a melhor, nem a única forma de olhar para a natureza. Ou seja: fomos ensinados por enunciações e imagens que nos acessam continuamente que a natureza ideal seria aquela das fotografias do Sebastião Salgado. Mas também somos interpelados por outros discursos sobre natureza bastante diferentes e que também nos convocam e nos incitam a fazer negociações entre essas distintas formas de pensar o que seria a natureza e como podemos nos relacionar com ela. Além disso, ainda no vídeo a que nos referimos, Žižek (2018) provoca significados assentados sobre natureza, dizendo que

\footnotetext{
essa noção de natureza, [vista] como harmônica, orgânica, equilibrada, reprodutiva, quase um ser vivo, que seria então perturbada, denegrida pela atividade humana, explorada tecnologicamente etc. É, eu acho uma versão secular do mito religioso do pecado original. E a resposta devia ser que não há pecado algum, que somos parte da natureza. E mais, não existe "uma natureza", de fato. Natureza não é uma totalidade em equilíbrio que o humano possa perturbar. A natureza é uma grande série de catástrofes inimagináveis (trecho do vídeo).
}

Ainda que na obra de Bruno Latour encontremos uma abordagem que desconstrói a noção de natureza de forma muito mais rigorosa, aprofundada e filosoficamente embasada do que nesse vídeo postado no YouTube, acredito que a simplicidade das formulações e provocações feitas por Žižek (2018) pode ressoar de uma maneira interessante no campo da Educação Ambiental. Talvez tenha me capturado o jeito certeiro com que ele toca em questões muito relevantes que são elaboradas na obra de diversos autores, mas de forma bem mais extensa e um pouco "menos palatável". Claro, como em toda síntese, os aspectos mencionados pelo filósofo esloveno carecem de aprofundamento. Não obstante, considero sua fala especialmente produtiva para mobilizar questionamentos desestabilizadores, contribuindo com a desconstrução de certezas que temos sobre natureza, meio ambiente e outros temas que são caros à Educação Ambiental.

Sendo assim, no excerto anterior, Žižek (2018) não apresenta nenhuma grande novidade para as pessoas que têm alguma familiaridade com debates pós-modernos sobre as operações de construção do conceito de natureza. Todavia, ele opera com palavras que alocam significações incisivas e que, para retomar a metáfora que venho usando, são potentes criadoras de ruínas. Dizer que a natureza dos ecologistas é uma versão secular do pecado 
SAMPAIO, Shaula Maíra Vicentini de. Como criar uma paisagem em ruínas? Deslocamentos, desconstruções e a insistência de pensar a Educação Ambiental no Antropoceno.

original, que não podemos ser considerados pecadores porque somos parte da natureza e, depois, que nem existe natureza de fato, é espalhar significantes que nos dão a pensar, que suscitam indagações e inquietações. Julgo ser necessário assinalar também que Žižek (2018), quando fala que "somos parte da natureza", não está se valendo daquele reprisado enunciado que compõe a trama de discursos ambientalistas, segundo o qual os seres humanos se afastaram da natureza e agora precisam ser reconectar com ela. Não está em jogo aqui pensarmos numa ação humana que já foi considerada positiva no passado (como uma reedição do mito do pecado original, como refere o filósofo), o que nos remete a um discurso nostálgico que costuma circular pela Educação Ambiental, como já mostrou Grün (1996). Ao contrário disso, no vídeo ele defende que devemos cortar de vez as nossas raízes e nos tornarmos cada vez mais artificiais! Em suas palavras, a "natureza" da Terra está absolutamente adaptada às intervenções humanas, à "contaminação" humana. Por isso, não deveríamos nos preocupar em suspender ou minimizar as ações humanas no ambiente: "a humanidade não tem como retroceder" (ŽIŽEK, 2018) ${ }^{4}$. Não é preciso concordar com essas afirmações, mas é interessante perceber que o filósofo traz à tona, com seu estilo peculiar, algumas questões que pairam nas discussões recentes sobre Antropoceno muito antes de se disseminarem os inúmeros discursos que circulam hoje sobre este tema.

\section{Por fim, um quase-manifesto sobre a insistência de pensar a Educação Ambiental}

Gostaria de reforçar mais uma vez que não tive a pretensão de exaltar ou idealizar a perspectiva promovida por Žižek (2018) ou por Latour, Scwartz e Charvolin (1998). O que me moveu na escrita deste texto foi a busca de posicionamentos teóricos que ajudassem a pensar na Educação Ambiental como uma paisagem em ruínas. Logo, lancei mão de autores que promovem alguns desmoronamentos em conceitos que, a meu ver, são cruciais no delineamento de uma paisagem da Educação Ambiental bastante estável - talvez demasiadamente estável. As fraturas provocadas pelos escritos e ditos desses intelectuais não precisam ser permanentes; podem ser transgredidas e contestadas. Poderiam, inclusive, ser outros autores os meus convidados para imaginarmos uma Educação Ambiental em ruínas, que imprimiriam outras provocações e desconstruções, catalisando outros desdobramentos argumentativos. O que importa é a sua capacidade de estremecer significados muito

\footnotetext{
${ }^{4}$ Frase retirada da fala de Žižek no vídeo.
} 
SAMPAIO, Shaula Maíra Vicentini de. Como criar uma paisagem em ruínas? Deslocamentos, desconstruções e a insistência de pensar a Educação Ambiental no Antropoceno.

assentados e fixos e, desse modo, abrir fissuras para que outras narrativas, outras imagens, de natureza(s), ambiente(s), associações entre humanos e não humanos possam vir a povoar as paragens da Educação Ambiental. Sem a menor pretensão de responder todas as perguntas que ficaram espalhadas por este texto, penso ter suscitado mais indagações acerca de uma suposta língua com a qual pensamos nos comunicar em Educação Ambiental e sobre as subversões e embaralhamentos que poderíamos fazer incidir nesta língua, tornando-a viva, vibrante, inventiva.

Mas pergunto ainda: uma educação ambiental em ruínas poderia nos ajudar a nos mover neste mundo por um fio? Sem a pretensão de me estender em reflexões sobre essa questão que não é nada simples, gostaria de demarcar uma posição quanto a ela. Uma posição afirmativa apesar de tudo. Como já falei antes, insisto na educação ambiental, apesar de um certo cansaço com algumas (meta)narrativas desgastadas, cantilenas que repetem slogans que não aguentamos mais ouvir. Insisto na educação ambiental apesar do pragmatismo que conforma e padroniza muitas das suas práticas e discursos, principalmente quando domados e esterilizados pelos carimbos das políticas públicas. Apesar disso tudo, não me parece impossível pensar numa educação ambiental que não ceda às tentações de normatizar e conscientizar, que restabeleça sua radicalidade por estar sempre se refazendo, se rearticulando. E que, ao invés de se declarar interdisciplinar como se isso fosse algo natural ou autoevidente, experimente se desterritorializar, encontrando com a arte, com a cultura, com a antropologia, com o cinema, com a literatura, com movimentos sociais, com saberes nãoacadêmicos... Nesse meu quase-manifesto, desejo uma educação ambiental (ou educações ambientais) que resista às constantes tentativas de curricularização, de delimitação de fronteiras (que se encorpam em bancos de dados, estados da arte e um sem número de balanços).

Gosto de imaginar e quero me engajar com uma educação ambiental que se escreva e inscreva no presente, para o presente, e que nos ajude a inventar novos mundos e a nos reinventar na relação com estes mundos... Danowsky e Viveiros de Castro comentam que, "quando as escalas da finitude coletiva e da finitude individual entram em uma trajetória de convergência, essa verdade cognitiva se torna subitamente uma verdade afetiva difícil de administrar" (2014, p. 29). Em um instigante diálogo com pesquisadores e filósofos do mundo todo, os autores discorrem sobre a cada vez mais concreta possibilidade de estarmos vivendo o fim do mundo. No entanto, já no final do livro, eles nos lembram que há muitos mundos no 
SAMPAIO, Shaula Maíra Vicentini de. Como criar uma paisagem em ruínas? Deslocamentos, desconstruções e a insistência de pensar a Educação Ambiental no Antropoceno.

Mundo. Há também a possibilidade de inventarmos novos mundos. Mas isso passa, certamente, pela reinvenção de nós mesmos, pela reescrita do que somos.

Num pequeno texto chamado "Escrever como se fosse o fim do mundo", Carlos Skliar $\operatorname{diz}$ assim:

\footnotetext{
Escrever, talvez, como se se tratasse do fim do mundo. Como se já não houvesse tempo, nem palavras, mas um abismo existencial diante do qual só cabe a escrita. É somente um ponto de partida, talvez apenas uma imagem: escrever, talvez, como se já não tivéssemos nem tempo, nem mundo. Mas é também uma posição é uma forma de expor-se: nesse limite, nesse abismo, nesse último fôlego em que vale a pena se perguntar sobre a palavra e seus gestos. A humanidade já viveu várias experiências como se se tratasse do fim do mundo. Em ocasiões pôs-se de joelhos ou talvez agachada. Outras vezes soltou esse grito intraduzível e pungente do limite. E também se rebelou (2014, p. 120).
}

Acredito que o meu grito, a minha escritura, a maneira como eu encontro para me posicionar diante do que pode ser o fim do mundo como conhecemos, ou do que alguns vêm chamando de Antropoceno, enfim, de um mundo que se transforma de maneira talvez irreversível, é através do meu ofício de educadora e, mais especificamente, trabalhando com educação em suas múltiplas conexões com as naturezas, com os ambientes. Esse é o terreno onde eu continuo desejando me mover e me reinventar.

\section{Referências}

AMORIM, Antônio Carlos R. Tapete de grãos de areia ou as práticas escolares como percursos-ruínas do currículo em ciências acontecendo. Educação em foco, Juiz de Fora, v. 8, n. 1, p.79-100, mar./ago. 2003.

CALVINO, Ítalo. As cidades invisíveis. São Paulo: Companhia das Letras, 1990.

CARVALHO, Isabel C. M. Educação ambiental: a formação do sujeito ecológico. São Paulo: Cortez, 2004.

CARVALHO, Isabel C. M. A invenção ecológica: narrativas e trajetórias da educação ambiental no Brasil. Porto Alegre: Editora da Universidade, 2001.

DANOWSKI, Déborah; VIVEIROS DE CASTRO, Eduardo. Há um mundo porvir? Ensaio sobre os medos e os fins. Desterro, Florianópolis: Cultura e Barbárie, 2014. 
SAMPAIO, Shaula Maíra Vicentini de. Como criar uma paisagem em ruínas? Deslocamentos, desconstruções e a insistência de pensar a Educação Ambiental no Antropoceno.

FOUCAULT, Michel. Microfísica do poder. Rio de Janeiro: Graal, 2003.

GARRÉ, Bárbara Hees; HENNING, Paula Corrêa. O enunciado de terror e medo pela perda do planeta: modos de constituir o discurso de crise ambiental na atualidade. In: REUNIÃO ANUAL DA ANPED, 36., Goiânia. Anais [...]. Goiânia, UFG, 2013. P.1-15.

GODOY, Ana. A menor das ecologias. São Paulo: Editora da Universidade de São Paulo, 2008.

GRÜN, M. Ética e educação ambiental: uma conexão necessária. Campinas: Papirus, 1996.

GRÜN, M. A produção discursiva sobre educação ambiental. In: VEIGA-NETO, Alfredo. (org.). Crítica pós-estruturalista e educação. Porto Alegre: Sulina, 1995. p. 159-184.

LARROSA, Jorge. Una lengua para la conversación. In: LARROSA, Jorge; SKLIAR, Carlos. (orgs.). Entre pedagogía y literatura. Buenos Aires: Miño y Dávila, 2006. p. 2539.

LATOUR, Bruno. Políticas da natureza: como fazer ciência na democracia. Bauru: EDUSC, 2004.

LATOUR, Bruno; SCHWARTZ, Cécile; CHARVOLIN, Florian. Crises dos meios ambientes: desafios às ciências humanas. In: ARAÚJO, Hermetes R. (org.). Tecnociência e cultura: ensaios sobre o tempo presente. São Paulo: Estação Liberdade, 1998. p. 91125 .

SANÍN, Ricardo. A ecologia é o ópio do povo: entrevista com Slavoj Žižek. Magis Revista da Unisinos, Porto Alegre, n. 05, dez. 2009/jan. 2010. Disponível em: http://slavoj-zizek.blogspot.com.br/2010/01/ecologia-e-o-opio-do-povo-entrevista.html. Acesso em: 10 ago. 2013.

SCOTTO, Gabriela; CARVALHO, Isabel Cristina de Moura; GUIMARÃES, Leandro Belinaso. Desenvolvimento sustentável. Petrópolis: Vozes, 2007.

SKLIAR, C. Desobedecer a linguagem: educar. Belo Horizonte: Autêntica, 2014. 
SAMPAIO, Shaula Maíra Vicentini de. Como criar uma paisagem em ruínas? Deslocamentos, desconstruções e a insistência de pensar a Educação Ambiental no Antropoceno.

SILVA, Tomaz T. O adeus às metanarrativas educacionais. In: SILVA, Tomaz T. (org.). O sujeito da educação: estudos foucaultianos. Petrópolis: Vozes, 1994. p. 247-258.

VEIGA-NETO, Alfredo. Foucault e a educação. Belo Horizonte: Autêntica, 2005.

VEIGA-NETO, Alfredo. Olhares. In: COSTA, Marisa V. (org.). Caminhos investigativos I: novos olhares na pesquisa em educação. Rio de Janeiro: DP\&A, 2002. p . 23-38.

ŽIŽEK, Slavoj. Multiculturalismo o la lógica cultural del capitalismo multinacional. In: JAMESON, Fredric; ŽIŽEK, Slavoj. (orgs.). Estudios culturales. Reflexiones sobre el multiculturalismo. Buenos Aires: Paidós, 2005. p. 137-188.

ŽIŽEK, Slavoj. A ecologia radical de Slavoj Zizek. (21m09s). Disponível em: https://www.youtube.com/watch?v=rwPe-Kml5AI. Acesso em: 21 mar. 2018. 